\title{
La crisis de la democracia en la época de weimar y en el siglo XXI
}

\author{
The crisis of democracy \\ in the Weimar era and \\ in the 21st century
}

\author{
FRANCISCO BALAGUER CALLEJÓN \\ Catedrático de Derecho Constitucional. \\ Universidad de Granada. \\ balaguer@ugr.es
}

https://doi.org/10.7203/cc.1.19046

Fecha de recepción: 28/09/2020

Fecha de aceptación: 18/11/2020

\section{Resumen}

En este trabajo se realiza una comparación entre la crisis democrática y constitucional de la época de Weimar y la crisis actual. Se argumenta que desde entonces se han desarrollado tres tipos de anticuerpos frente a involuciones democráticas radicales en sentido totalitario. Esos tres anticuerpos se derivan de la propia debilidad de los Estados en el contexto de la globalización, de la integración supranacional y de la normatividad de la constitución. Se analiza también la crisis de legitimidad de la constitución en el siglo XXI frente a los factores de legitimación actuales, la tecnología y economía.

\section{Palabras clave}

Constitución de Weimar; democracia; legitimidad de la constitución; globalización.

\begin{abstract}
This Work makes a comparison between the democratic and constitutional crisis of the Weimar era and the current crisis. It is argued that since then three types of antibodies have been developed against radical democratic involutions in a totalitarian sense. These three antibodies are derived from the very weakness of the States in the context of globalization, supranational integration and the normativity of constitution. The crisis of legitimacy of the constitution in the 21st century is also analysed in the face of current legitimation factors, technology and economy.
\end{abstract}

\section{Keywords}

Weimar Constitution; democracy; legitimacy of the constitution; globalization. 
I. Introducción. - II. Las condiciones históricas de la Constitución de Weimar. - III. Las similitudes con la época actual. Contexto internacional y crisis económica. - IV. Las diferencias con la época actual. Globalización, integración supranacional y normatividad de la Constitución. - V. La vertiente retórica de la crisis democrática. - VI. Crisis de legitimidad en la época de Weimar y en el siglo XXI. - VII. Conclusiones. Bibliografía.

\section{Introducción}

En el año 2019, que parece tan lejano desde que comenzó la crisis sanitaria, celebramos el centenario de la Constitución de Weimar, un texto constitucional y una época histórica que han marcado profundamente el desarrollo del constitucionalismo que hoy conocemos. En el período de entreguerras se definieron las líneas teóricas que darían lugar a la transición del Estado legal de Derecho al Estado constitucional de Derecho, que se consolidaría después de la Segunda Guerra Mundial, singularmente con la Ley Fundamental de Bonn (que también cumplió años, 70) y con la Constitución italiana de 1948 (cuyo setenta aniversario celebramos el año anterior junto con el cuarenta aniversario de la Constitución española). Los grandes nombres que construyeron la teoría constitucional del Estado en Alemania o en Italia durante la época de Weimar darían lugar a nuevos paradigmas como la normatividad de la Constitución o el Estado social, que están en la base de los grandes pactos que alumbraron el constitucionalismo en el que se inspiran muchos sistemas constitucionales en Europa y en el mundo. Figuras como Hans Kelsen o Hermann Heller, pero también Rudolf Smend, Santi Romano o Costantino Mortati abrirían espacios de debate y reflexión sobre el sentido profundo de la Constitución y sobre la esencia misma de la democracia'.

Fueron tiempos en los que la tensión política se manifestó como lucha por la soberanía, por obtener el poder absoluto del Estado para imponer el dominio ilimitado de la mayoría. Esa peculiaridad de la época es lo que permitiría caracterizarla desde el punto de vista constitucional como un período de "constitucionalismo antagónico". La apertura del proceso político, con la ampliación del sufragio, superando las limitaciones del sufragio censitario propio del primer constitucionalismo, se va a vertebrar a través de una confrontación radical entre sectores que perciben la democracia como un modo de acceder al poder para imponer su ideario sobre el conjunto de la sociedad. Las consecuencias de esa manera de entender la política son conocidas y el retroceso civilizatorio que supuso la llegada del fascismo y el nazismo al poder sigue siendo hoy una advertencia para aquellos grupos que conciben la política como la voluntad

1 Sobre estas cuestiones, Balaguer Callejón (en prensa). 
incondicional de la mayoría gobernante. Por eso, más allá de la celebración de lo que la Constitución de Weimar supuso de avance en el constitucionalismo (en muchos ámbitos, pero especialmente en materia de derechos sociales), el período de Weimar sigue figurando en la memoria como una oportunidad perdida debido a la incapacidad de la Constitución y de la sociedad en su conjunto para hacer frente a la barbarie.

\section{Las condiciones históricas de la Constitución de Weimar}

La Constitución de Weimar fue la consecuencia no deseada de una derrota no esperada en la Guerra y, por tanto, de la necesidad de reconfigurar un régimen político en condiciones muy desfavorables ${ }^{2}$. Las presiones internacionales determinaron ya algunas opciones constituyentes y generaron un entorno hostil a la propia Constitución, que se agravó con las crisis económicas que tuvo que soportar la sociedad alemana durante el período de Weimar y el pago de las reparaciones de guerra.

Pese a ello, la Constitución contiene aportaciones interesantes que responden al intento de dar respuesta a los problemas de la época. En clave alemana, la Constitución de Weimar incorpora una combinación de poderes que busca el equilibrio compensando las amplias potestades del Parlamento con la atribución de poderes especiales al Presidente de la República (Esteve Pardo, 2019: 15, 31) así como con mecanismos de democracia directa. Al mismo tiempo incluye una vertiente social que responde a una específica tradición germánica pero que contiene nuevos desarrollos, siguiendo la estela de la Constitución de México de 1917. En clave europea, la Constitución aporta ese contenido social y laboral en relación con los derechos e incorpora al constitucionalismo europeo el germen de lo que después sería el Estado social y democrático de Derecho.

Sin embargo, la crisis de Weimar se vería impulsada por diversos factores. En primer lugar factores exógenos, como el hecho de que la Constitución tuvo un competidor muy importante en el Tratado de Versalles, lleno de disposiciones concretas que afectaban de manera directa al pueblo alemán, mucho más que las propias disposiciones constitucionales de Weimar (Rürup, 1992: 125). El Tratado de Versalles se configuraría así en gran medida como la Constitución de Weimar en negativo pero con una dimensión más práctica, tangible y efectiva que la propia Constitución. El Tratado sería el gran impulsor del nacionalsocialismo y, como indica Andreas Wirsching (2019: 39), cada vez que se producía alguna tensión en Alemania como consecuencia de la aplicación del Tratado, aumentaba la proyección de los nacionalistas radicales.

También hubo factores endógenos que favorecieron la crisis de Weimar. La propia organización interna del poder, por más que en general pueda valorarse positivamente al favorecer el equilibrio de poderes, finalmente no resultó positiva en la dinámica política de la época. Igualmente tuvo su importancia la escasa relevancia de los Länder en la Constitución, con un federalismo débil³,

2 Como indica Wirsching (2019: 19-20), la derrota vino de improviso, sin que hubiera existido previamente en Alemania una convicción extendida de que la guerra se fuera a perder, lo que generó en la cultura política de la Alemania posterior un déficit de conciencia de la realidad. El resultado es que a la República de Weimar se le atribuirá el peso de la derrota mientras que en el campo conservador se mantenía el recuerdo de la Alemania imperial en el esplendor de su grandeza nacional.

3 Como indica Esteve Pardo (2019: 30), en la Constitución de Weimar se dio una marcada tendencia a la concentración del poder en los órganos de la Federación. 
que impidió un contrapeso de poder como ocurre actualmente en la República Federal.

En todo caso, las tensiones políticas y sociales de la época decidieron el destino de una Constitución que nada podía hacer frente a los enfrentamientos radicales que convirtieron a Alemania en un campo de batalla, como consecuencia de la sucesión de crisis económicas y de la debilidad de un Estado que había surgido de una derrota bélica y que no consiguió adaptar sus estructuras al nuevo orden constitucional.

\section{Las similitudes con la época actual. Contexto internacional y crisis eco- nómica}

Las condiciones en las que se desenvuelven los procesos políticos actuales nos retrotraen al período de Weimar. En primer lugar por la crisis económica de base $y$, en segundo lugar, por la fragmentación y la radicalización progresiva de la sociedad que ha producido. Ahora no es el Tratado de Versalles sino el desarrollo acelerado de la globalización lo que limita la acción estatal e incide de manera muy intensa en la ordenación económica, provocando transformaciones importantes de los sectores productivos y un malestar social muy extendido. De alguna manera, la imagen del Tratado de Versalles como Constitución en negativo podría trasladarse en parte a la globalización en la medida en que está minando económica, cultural y políticamente los pilares sobre los que se construyeron las constituciones normativas.

Estas condiciones de crisis, unidas al agravamiento de la tensión y de la radicalización que se promueven en los procesos comunicativos por las grandes compañías tecnológicas de alcance global, están generando la progresiva implantación de un concepto de democracia incompatible con la idea de democracia pluralista y constitucional, lo que supone un retroceso en nuestra cultura constitucional (Balaguer Callejón, 2019a). La idea de una democracia que responde a la voluntad única del "pueblo" que se pretende monopolizar por parte de determinados movimientos políticos, la expulsión simbólica de la comunidad política de aquellos que no defienden las mismas ideas, la contraposición que se hace entre democracia y derecho, cuestionando cualquier limitación jurídica al poder político y otros muchos rasgos que vemos cotidianamente en los procesos políticos de muchos países europeos evidencian que la democracia pluralista y constitucional está sufriendo un grave deterioro que puede dar lugar a una involución democrática.

\section{Las diferencias con la época actual. Globalización, integración suprana- cional y normatividad de la Constitución}

Existen muchas lecciones de Weimar que podemos extraer para nuestro tiempo, pero también tenemos que tener en cuenta que las condiciones históricas son muy diferentes. Hay cuando menos tres factores que han transformado esencialmente el contexto sobre el que los nuevos movimientos reaccionarios actúan respecto del de la época de Weimar. El primero de ellos tiene que ver con la globalización y la debilidad creciente que ha generado en el Estado, cada vez más sometido a agentes globales que no puede controlar y que determinan en gran medida sus políticas. El segundo tiene que ver con la integración supranacional (en el caso de los países europeos) que incorpora límites a la actividad estatal protegiendo los valores democráticos, por más que esta protección no haya 
sido lo eficaz que sería deseable hasta el presente. El tercero tiene que ver con la configuración interna del orden constitucional por medio de constituciones normativas que establecen límites jurisdiccionales al poder del Estado que no existían (aunque estaban surgiendo en algunos países) en la época de Weimar.

El primero de los factores señalados nos indica que el Estado nacional ha perdido gran parte de su poder político en este tiempo de globalización, lo que determina que la conquista del poder del Estado no suponga ahora la posibilidad de establecer un régimen totalitario. Los agentes financieros globales limitan las grandes opciones económicas del Estado y, por tanto, la acción de los gobiernos. Del mismo modo, las compañías tecnológicas globales inciden en la comunicación política y en los procesos democráticos condicionando también las opciones políticas del Estado (Balaguer Callejón, 2018). Podríamos decir que, mientras el período de Weimar reflejó la crisis del Estado liberal, la época actual refleja la crisis del Estado como tal, del Estado tout court sin adjetivos. Esta es una diferencia importante con la época de Weimar porque las posibilidades de acción política por parte de las mayorías en el poder son ahora más limitadas.

Esas limitaciones no se derivan solo del avance de la globalización en el plano externo sino también de los procesos de integración supranacional cuando alcanzan un nivel importante de desarrollo como es el caso de Europa. La integración europea sigue siendo, pese a que no consiga la efectividad que sería necesaria, una garantía frente a involuciones democráticas de los Estados miembros (Balaguer Callejón, 2010). No es fruto del azar que los movimientos euroescépticos suelan ser al mismo tiempo los que representan más fielmente estas tendencias involutivas desde el punto de vista constitucional. Con todos los reparos que se le puedan poner a la Unión Europea, el proyecto de integración ha sido históricamente un instrumento de limitación de la soberanía estatal que genera un nuevo nivel de la división de poderes y del control del poder. Ese nivel supranacional de control, pese a las deficiencias que ha mostrado en los últimos años en relación con países con gobiernos de tendencia iliberal, se inspira en los valores y principios del patrimonio constitucional europeo contra los que esas tendencias han luchado siempre, porque suponen un límite a la voluntad incondicionada de la mayoría parlamentaria que ellos defienden. Desde esa perspectiva, preservar el proyecto europeo contribuye a preservar también el patrimonio constitucional europeo.

Pero las limitaciones al poder del Estado no proceden solamente del exterior sino que también tienen una vertiente interna derivada del desarrollo del constitucionalismo después de la Segunda Guerra Mundial, como consecuencia precisamente de la experiencia negativa del período de Weimar y de la implantación de las nuevas constituciones normativas. Las constituciones normativas aprenderían de esta trágica experiencia histórica y refundarían el constitucionalismo sobre nuevas bases.

Estos límites externos e internos suponen un importante freno a un desarrollo en sentido totalitario de la crisis de la democracia. Sin embargo, no puede dejar de señalarse que tienen un alcance y un valor muy diferente desde el punto de vista de la democracia y del constitucionalismo. Los que se derivan de la globalización contribuyen a debilitar también a la propia Constitución y a la democracia al tiempo que limitan el poder del Estado. Los que parten de la integración supranacional contribuyen a garantizar la democracia interna de los Estados, pero desde una estructura institucional que, paradójicamente, no es todavía plenamente democrática. Por su parte, los derivados de la normatividad de la Constitución y de la democracia constitucional que se establece en las constituciones internas de los Estados se inscriben, desafortunadamente, dentro de una tendencia creciente a la marginación de la Constitución, derivada 
del proceso de globalización y del creciente poder de los grandes agentes financieros y tecnológicos globales.

\section{La vertiente retórica de la crisis democrática}

A pesar de que los límites antes enunciados dificultan una regresión democrática estructural que suponga, como en la época de Weimar, la implantación de regímenes totalitarios, los avances sociales que se han consolidado bajo el régimen constitucional están ahora en peligro en muchos países. En algunos de ellos ya lo estaban antes del Brexit y de las elecciones presidenciales norteamericanas de 2016. En otros se han desarrollado nuevas tendencias iliberales con una presencia variable en el espacio público. Países con una tradición constitucional relevante están gobernados actualmente por movimientos políticos que no respetan los derechos de las minorías, que promueven actitudes xenófobas o racistas, que quieren revertir los avances en materia de igualdad, en especial de igualdad de género, y que se consideran legitimados por el voto popular para imponer su programa político sin limitaciones jurídicas o constitucionales. Es justamente la presión sobre el poder judicial o sobre la jurisdicción constitucional lo que resulta más característico de estas tendencias políticas. La apelación directa al "pueblo" o la "nación" y la confrontación permanente con el Estado de Derecho de una pretendida "democracia" que se justifica a través de esos referentes, incluso cuando ni siquiera se tiene la mayoría del voto popular, es una constante en estos movimientos ${ }^{4}$.

La mirada se vuelve inevitablemente a Weimar cuando vemos estas tendencias que se están desarrollando en todo el mundo, con el dopaje intencionado de grandes agentes globales a través de las redes sociales y por medio de la falsificación de noticias y la utilización de perfiles falsos y de procesos automatizados para generar climas de opinión. Sin embargo, el contexto de Weimar y el actual son muy diferentes. La dificultad que estos grupos experimentan para llevar a cabo sus programas políticos tiene que ver justamente con las transformaciones históricas que se han producido en los últimos cien años. Los fascismos de la época de Weimar pugnaban por conquistar el poder del Estado, que seguía siendo en esa época un centro de poder real y ante el cual se postulaban como alternativa global frente a otros movimientos sociales y políticos. Las banderas, los himnos propios, los uniformes incluso, eran la manifestación de una vocación de ordenación total de la vida social que era posible dentro de un Estado nacional que concentraba el poder político, social y económico.

De los condicionantes globales, supranacionales y constitucionales que, como hemos indicado, limitan el poder del Estado, quizás el más importante lo representa la globalización. Los agentes globales y la dinámica de la globalización se sitúan más allá de las capacidades del Estado y suponen una limitación estructural de su "soberanía" que no es recuperable con su mera voluntad. Que la integración europea es un límite igualmente consistente lo evidencia justamente el Brexit (Balaguer Callejón, 2019), el único ejemplo que tenemos hasta ahora de intento de recuperación de la "soberanía" estatal frente a la Unión Europea y que hasta el momento sólo ha deparado una suma de calamidades a sus instigadores. Su consumación el 31 de enero de 2020, justo antes de que

4 Por lo demás, como indica Morelli (2019), se trata de un pueblo del que se predica una superioridad moral respecto de todos aquéllos que para los populistas, por diversas razones, no forman parte del pueblo. 
comenzara la crisis sanitaria, deja al Reino Unido en peores condiciones para la recuperación económica que tendrá que abordar, como el resto de los países europeos, en los próximos meses.

Por lo que se refiere a los límites internos derivados del desarrollo civilizatorio que han supuesto las constituciones normativas, su eficacia dependerá en gran medida de la propia sociedad y del grado de conciencia que haya conseguido acerca de la importancia de preservar un modelo de convivencia que ha hecho posible el bienestar y la paz en los países europeos hasta ahora. En última instancia, de la responsabilidad de la ciudadanía depende que estos movimientos pasen a la historia sin afectar a los fundamentos del constitucionalismo o que sigan avanzando.

De momento, el desarrollo de estas tendencias regresivas desde el punto de vista de la democracia pluralista parece muy condicionado por las limitaciones globales y supranacionales, por lo que está generando básicamente un discurso agresivo sin contenido real, que solo produce malestar e inestabilidad. En efecto, una gran parte de la tensión política de nuestra época, a diferencia de la de Weimar, está artificialmente dopada y se mueve en un terreno retórico más que en el de los daños irreversibles al sistema democrático. Estos movimientos están generando una narrativa ofensiva y antidemocrática que, de momento, es incapaz de articular en la práctica una transformación estructural del sistema constitucional en sentido regresivo.

Sin embargo, tampoco puede desconocerse que se trata de movimientos alimentados por agentes globales, que se sitúan fuera del control del Estado e incluso de las instancias supranacionales, lo que produce una inevitable inquietud desde el punto de vista constitucional. Esta retórica involucionista no debe minusvalorarse porque supone un retroceso cultural y civilizatorio respecto de los valores constitucionales y también por la afectación de los derechos de las minorías y de los inmigrantes, los grupos en los que centran sus ataques. Es igualmente importante por la inestabilidad que genera y porque contribuye a debilitar al Estado frente a los grandes agentes globales, financieros y tecnológicos, bloqueando la política y dificultando el control de esos agentes. En última instancia, debilita también la legitimidad del constitucionalismo contribuyendo a la crisis de la democracia y de la Constitución en el siglo XXI frente a los grandes agentes de legitimación de la globalización, el económico y el tecnológico.

\section{Crisis de legitimidad en la época de Weimar y en el siglo XXI}

La crisis de la época de Weimar se manifestó en el debate doctrinal que se generó en Alemania y también en Italia sobre la legitimidad de la Constitución. Manifestación de esa crisis será el intento de encontrar la fuente última de legitimación del ordenamiento, lo que dará lugar a distintas teorías. La crisis del Estado liberal conduce a la necesidad de buscar nuevos fundamentos para el orden constitucional y los grandes autores de la época construirán sistemas conceptuales a partir de los cuales se podría reconstruir la unidad ${ }^{5}$. Entre ellos los de Kelsen (1960) ${ }^{6}$,

5 Como indica Álvarez Álvarez (2011: 454), “durante el constitucionalismo de Weimar comenzó a desarrollarse con fuerza un estudio metapositivo de la Constitución, intentando reconstruir teóricamente una unidad política que el resultado poliédrico final de la Constitución de Weimar no había permitido reflejar".

6 Sobre la relación entre Kelsen y Schmitt véase De Miguel Bárcena y Tajadura Tejada (2018). 
fundamental, la decisión fundamental o la constitución material responderían a esa pretensión legitimadora y unitaria, siendo el paradigma kelseniano el que inspirará a las constituciones normativas y al Estado constitucional de Derecho.

En el contexto de la globalización también se han generado nuevos discursos relacionados con la mayor densidad constitucional del derecho internacional ${ }^{9}$ o con la situación de pluralismo constitucional ${ }^{10}$ propia del derecho constitucional de la integración supranacional. Entre ellos destaca especialmente el planteamiento de Peter Häberle (1999: 84 y ss.) sobre las constituciones parciales, que expresan una realidad constitucional compleja, como ocurre con el proceso la integración europea. Una teoría que está en la base de otros muchos desarrollos doctrinales.

Ciertamente, los problemas de legitimidad de nuestro tiempo no se limitan al ámbito del Estado y a los conflictos que se producen en su interior, como ocurrió en la época de Weimar ${ }^{11}$. No se trata ahora de reformular el orden constitucional del Estado liberal precisamente porque lo que está en crisis es el Estado como tal y no solamente un modelo específico de Estado.

En estas condiciones la crisis de legitimidad se está extendiendo a la propia Constitución que se ve incapaz de hacer frente, en el limitado ámbito estatal en el que interviene, a los grandes factores de legitimación del siglo XXI, que tienen un alcance global: la economía y la tecnología. Dos factores de legitimación que se han desvinculado de su relación histórica con el constitucionalismo moderno y han comenzado a plantearse como alternativas de progreso frente a la Constitución (Balaguer Callejón, 2020). La Constitución se ve marginada en el espacio público, incapaz de responder a la transformación de las pautas culturales que se están produciendo a impulsos de la tecnología y de la economía.

La posibilidad de establecer nuevos paradigmas que hagan frente a esta creciente pérdida de legitimidad resulta dificultada por el hecho de que la Constitución tiene un ámbito natural limitado a las fronteras estatales que no se corresponde con la realidad de los factores de poder que actúan ahora en el ámbito global. La misma debilidad del Estado que hace que los riesgos para la democracia y para la paz social sean hoy mucho menores que en la época de Weimar implica también, como faceta negativa, la debilidad de la Constitución y el declive de la

7 Por lo que se refiere a Schmitt, hará notar Francisco Ayala en la Presentación de la traducción al castellano de la Verfassungslehre, que él realizó en 1934, esa tensión entre unidad y heterogeneidad que se da entre los supuestos del Estado nacional que se heredan de la Monarquía absoluta y el pluralismo al que se abre la democracia liberal: "El Estado constitucional necesita contar con los supuestos creados por la Monarquía para la Nación; pero, a consecuencia del conjunto de derechos y libertades en que el régimen liberal consiste, ha de renunciar a toda clase de medios coactivos para mantener y restaurar aquellos supuestos; ha de consentir que crezcan y prosperen todas las tendencias dirigidas a quebrar la homogeneidad nacional"; de ahí la teoría de la decisión política fundamental de Schmitt que no es otra cosa que la incorporación al Estado liberal democrático de la vocación homogeneizadora de la Monarquía absoluta: "Debajo del Estado de Derecho duerme, en efecto, la Monarquía", dirá Ayala (1934/1996: 14 y ss.). Sobre Carl Schmitt véase Gómez Orfanel (1986).

8 Sobre la relación entre Mortati y Kelsen véase Balaguer Callejón (2017).

9 Sobre este debate véase Häberle (2019).

10 Sobre esta cuestión véase MacCormick (1995).

11 En realidad, como bien dice García López (2013: 532) por referencia a Schmitt, "Ias preguntas que encierra la reflexión constitucional de Schmitt se sitúan en el contexto de la crisis que a lo largo de todo el siglo XX ha venido enfrentando a dos ideologías adversarias. Mientras el actual momento post-histórico parece responder más bien a un proceso de declive, de decadencia de nuestros principios, nuestras técnicas sociales, y en definitiva de la manera de comprender el mundo que arranca de la llustración". 
cultura constitucional. En estas condiciones, la retórica populista ${ }^{12}$ y radical que se está extendiendo en muchos países junto con fenómenos tales como las fake news, la llamada posverdad y otros similares son expresión de una involución democrática que conduce a una democracia de muy baja calidad.

\section{Conclusiones}

La Constitución de Weimar, pese a sus innegables cualidades, abrió un período convulso en la historia de Alemania y del mundo debido a las condiciones históricas de la época, con la crisis del Estado liberal, que en Alemania eran especialmente adversas como consecuencia de las crisis económicas que se sucedieron en el periodo y la presión internacional constante como "Constitución en negativo" del Tratado de Versalles. La estabilidad constitucional que se inició con las constituciones normativas después de la Segunda Guerra Mundial se mantuvo durante el medio siglo siguiente evidenciando un progreso civilizatorio. El constitucionalismo aportará un modelo de convivencia basado en el consenso fundamental en torno a las variables democrática, social y normativa de la Constitución. Los grandes pactos constitucionales hicieron posible que la Constitución cumpliera sus funciones esenciales: la garantía de los derechos, el control del poder y la canalización de los conflictos sociales a través del Derecho. Se superó así el antagonismo radical del período de Weimar y la concepción de la democracia basada en la voluntad sin límites de la mayoría, sin controles jurídicos de naturaleza constitucional.

Pero en el siglo XXI retornará ese antagonismo radical con el desarrollo de movimientos populistas e iliberales, que propugnan una involución democrática basada en la voluntad soberana de la mayoría. Esos movimientos se arrogan la representatividad absoluta del "pueblo", identificado de nuevo como un colectivo homogéneo al que no pertenecen los que no comparten su ideario. Estas tendencias nos hacen volver la mirada a Weimar con la inquietud inevitable de que pueda repetirse de algún modo la terrible deriva histórica que tuvo la república alemana. Sin embargo, las condiciones históricas han cambiado esencialmente en el contexto de la globalización con el avance de grandes agentes globales que en el plano económico o en el tecnológico ocupan ahora las principales posiciones de poder que antes se ejercitaban por el Estado dentro del marco constitucional. Bajo estas nuevas condiciones históricas, la lógica económica y tecnológica externa al Estado se impone sobre la política y determina la capacidad de acción de las mayorías gobernantes.

En comparación con la época de Weimar, los movimientos reaccionarios que hoy pueden ocupar el poder se enfrentan a una serie de límites en el plano interno derivados del propio desarrollo histórico del constitucionalismo, como la normatividad de la Constitución y la jurisdicción constitucional. A esos condicionantes internos se unen en Europa los derivados de la integración supranacional que supone una nueva dimensión de la división de poderes y una garantía adicional de la democracia en los Estados miembros (aunque no esté funcionando con la efectividad deseada). Por último, la globalización impone su propia lógica, generando una creciente debilidad del poder estatal frente

12 Respecto del populismo tiene toda la razón Häberle (2018) cuando afirma: "Me niego a regalarle la palabra populus a los populistas. Pensemos en Cicerón y su res publica, res populis, en los romanos con su senatus populus romanus, en el no menos famoso we the people, en la inscripción del Reichstag 'el pueblo alemán', o en el hecho de que, en la mayoría de los Estados, se considere que el poder judicial se expresa 'en nombre del pueblo'". 
a los agentes globales. Todas estas nuevas condiciones históricas funcionan como "anticuerpos" frente a involuciones democráticas radicales y dan como resultado que una gran parte del peligro involucionista que estos movimientos suponen se disuelva en una retórica agresiva y antidemocrática incapaz de articular en la práctica una transformación estructural del sistema constitucional en sentido regresivo.

Esta retórica involucionista no debe minusvalorarse, sin embargo. No solo por lo que supone de retroceso cultural y civilizatorio respecto de los valores constitucionales y por lo que puede generar y está generando de afectación a los derechos de las minorías y de los inmigrantes, los grupos en los que centran sus ataques. Es también importante por la inestabilidad que genera y porque contribuye a debilitar al Estado frente a los grandes agentes globales, financieros y tecnológicos, bloqueando la política y dificultando el control de esos agentes. En última instancia, debilita también la legitimidad del constitucionalismo contribuyendo a la crisis de la democracia y de la Constitución en el siglo XXI frente a los grandes agentes de legitimación de la globalización, el económico y el tecnológico.

Revitalizar la democracia y la constitución requiere de una reconfiguración del constitucionalismo, no ya en relación exclusiva con el Estado como en el periodo de Weimar sino en el control del poder que hoy se ejercita por los grandes agentes globales fuera del Estado pero sobre el Estado y la sociedad. A pesar de su creciente debilidad, el Estado y la Constitución tienen todavía mucho que decir en su función de mediadores entre las instancias globales y la ciudadanía, especialmente allí donde las instancias supranacionales no existan o no alcancen a complementar esa función de mediación.

\section{Bibliografía}

Álvarez Álvarez, L. (2011). La Constitución de Weimar ¿Una república sin republicanos? Historia Constitucional, 12, 443-459.

Ayala, F. (1934/1996). Presentación a Carl Schmitt. Teoría de la Constitución. Alianza Editorial: Madrid.

Balaguer Callejón, F. (2010). A divisão territorial do poder num contexto supranacional. O exemplo da Espanha na União Europeia. En A. Ramos Tavares, I. Wolfgang Sarlet y G. Salomão Leite (eds.). Estado Constitucional e Organização do Poder. São Paulo (Brasil): Editora Saraiva.

Balaguer Callejón, F. (2017) Potere costituente e limiti alla revisione costituzionale visti dalla Spagna. En F. Lanchester (a cura di). Costantino Mortati. Potere costituente e limiti alla revisione costituzionale (pp. 85-112). Padova: Cedam.

Balaguer Callejón, F. (2018). Las dos grandes crisis del constitucionalismo frente a la globalización en el siglo XXI. Nomos. Le attualità nel diritto, 2. Disponible en: https://www.nomos-leattualitaneldiritto.it/wp-content/uploads/2018/09/ Callehon.-conv-11.05.pdf

Balaguer Callejón, F. (2019a). Redes sociales, compañías tecnológicas y democracia. Revista de Derecho Constitucional Europeo, 32. Disponible en: https:// www.ugr.es/ redce/REDCE32/articulos/O4 F BALAGUER.htm

Balaguer Callejón, F. (2019b). La Unión Europea frente al Brexit y otros procesos disgregadores en el contexto global. En F. Balaguer Callejón y J. Tudela Aranda (coords.). Perspectivas actuales del proceso de integración europea (pp. 23-41). Madrid: Marcial Pons.

Balaguer Callejón, F. (2020). Constitution, démocratie et mondialisation. La légitimité de la Constitution face à la crise économique et aux réseaux sociaux. 
En VV.AA. Mélanges en l'honneur du Professeur Dominique Rousseau. Constitution, justice, démocratie. Paris: LGDJ.

Balaguer Callejón, F. (2021). La teoria delle fonti del diritto nello Stato costituzionale. En Scritti in onore di Antonio Ruggeri. (En prensa).

De Miguel Bárcena, J. y Tajadura Tejada, J. (2018). Kelsen versus Schmitt: política y derecho en la crisis del constitucionalismo. Madrid: Guillermo Escolar Editor.

Esteve Pardo, J. (2019). El pensamiento antiparlamentario y la formación del Derecho público en Europa. Madrid: Marcial Pons.

García López, E. (2013). Carl Schmitt y la cultura política post-histórica: una hipótesis acerca de la renaissance anglosajona de Schmitt. Historia Constitucional, $14,525-532$.

Gómez Orfanel, G. (1986). Excepción y normalidad en el pensamiento de Carl Schmitt. Madrid: CEPC.

Häberle, P. (1999). Europa-Eine Verfassungsgemeinschaft? En P. Häberle (ed.). Europäische Verfassungslehre in Einzelstudien (pp. 84 y ss.). Baden-Baden: Nomos Verlagsgesellschaft.

Häberle, P. (2013). El constitucionalismo universal desde las constituciones parciales nacionales e internacionales. Siete Tesis. Direito Público, 54, 9-13. Disponible en: https://www.portaldeperiodicos.idp.edu.br/direitopublico/ article/view/2363/1219

Häberle, P. (2018). El constitucionalismo como proyecto científico. Revista de Derecho Constitucional Europeo, 29. Disponible en: https://www.ugr. es/ redce/REDCE29/articulos/O4 HABERLE.htm

Kelsen, H. (1960). Reine Rechtslehre. Viena: Verlag Franz Deuticke.

MacCormick, N. (1995). The Maastricht Urteil: Sovereignty Now. European Law Journal, I-3, 259-266.

Morelli, A. (2019). El reduccionismo populista y sus efectos en la representación política y en la jurisdicción. Revista de Derecho Constitucional Europeo, 31. Disponible en: https://www.ugr.es/ redce/REDCE31/articulos/05 MORELLI. $\underline{\text { htm }}$

Mortati, C. (1940/1998). La Costituzione in senso materiale. Milano: Giuffrè Editore. Rürup, R. (1992). Génesis y fundamentos de la Constitución de Weimar. Ayer, 5 , 125-158.

Schmitt, C. (1928/2017). Verfassungslehre. Berlín: Duncker \& Humblot.

Wirsching, A. (2019). Weimar, cent' anni dopo. La storia e l'eredità: bilancio di un'esperienza controversa. Roma: Donzelli Editore. 